BMJ Open

Ophthalmology

\title{
Generating evidence for planning eye care service delivery in an urban underprivileged population setting in Pune, Western India
}

Sucheta Kulkarni, ${ }^{\oplus 1}$ Shridevi Kondalkar, ${ }^{1}$ Islay Mactaggart, ${ }^{2}$ B R Shamanna, ${ }^{3}$ Azher Lodhi, ${ }^{1}$ Rohit Mendke, ${ }^{1}$ Jitesh Kharat, ${ }^{1}$ Rajesh Kapse, ${ }^{1}$ Kuldeep Dole, ${ }^{1}$ Madan Deshpande ${ }^{1}$

To cite: Kulkarni S, Kondalkar S, Mactaggart I, et al. Generating evidence for planning eye care service delivery in an urban underprivileged population setting in Pune, Western India. BMJ Open Ophthalmology 2019;4:e000202. doi:10.1136/ bmjophth-2018-000202

- Additional material is published online only. To view please visit the journal online (http://dx.doi.org/10.1136/ bmjophth-2018-000202).

Received 8 August 2018 Revised 4 July 2019 Accepted 5 July 2019
Check for updates

\section{(c) Author(s) (or their} employer(s)) 2019. Re-use permitted under CC BY-NC. No commercial re-use. See rights and permissions. Published by BMJ.

${ }^{1}$ Department of community ophthalmology, PBMA's H. V. Desai Eye Hospital, Pune, India ${ }^{2}$ Department of Clinical Research, London School of Hygiene and Tropical Medicine, London, UK

${ }^{3}$ School of Medical Sciences, University of Hyderabad, Hyderabad, India

\section{Correspondence to} Dr Sucheta Kulkarni; drsucheta. kulkarni@gmail.com

\section{ABSTRACT}

Purpose To estimate prevalence of blindness, diabetic retinopathy and causes of blindness through rapid assessment of avoidable blindness (RAAB) survey in Pune, India to develop an evidence base for planning urban eye care services.

Methods 'Rapid assessment of avoidable blindness and diabetic retinopathy' methodology was used. Compact segment sampling was used in each of the 60 selected electoral wards identified through cluster selection module of the RAAB software using probability proportionate to size method. Persons $>50$ years of age were enumerated from selected segments to achieve cumulative target of $60 /$ day by two teams. Participants underwent presenting and pinhole visual acuity (VA) testing in each eye. A torch light examination and direct ophthalmoscopy established cause of visual impairment/blindness if present. Data were entered into and analysed using RAAB software.

Results The response rate was 89.5\% (3221/3600), and $55.3 \%$ were women. Results of only RAAB module are presented in this paper. Age-standardised and sexstandardised prevalence of blindness was 1.3\% (95\% $\mathrm{Cl} 0.9$ to 1.8). Cataract was the most common cause of blindness $(45.7 \%)$ followed by overall posterior segment disorders (39.1\%). Cataract surgical outcome was good (VA>6/18) or very good (VA>6/12) in 805/1190 (67.6\%) cases. Cataract surgical coverage was $96.7 \%$. 'Need not felt' $(36.6 \%)$ and 'cost' (31.7\%) were the most common barriers for cataract surgery.

Conclusion Prevalence of blindness is showing declining trend in urban India. Cataract remains a major cause of blindness followed by posterior segment disorders. Social marketing, and referral linkages between community and service providers were planned after this survey.

\section{INTRODUCTION}

Despite collective global efforts, cataract continues to remain the principal cause of avoidable blindness. Demographic and epidemiological transition coupled with inadequate service delivery initiatives and health inequities across the world suggests that more efforts are required to address the cataract blindness. $^{1-3}$ There has been a significant

\section{Key messages}

What is already known about this subject?

- Globally declining prevalence of blindness is an already established fact. Cataract still remains the leading cause of blindness measuring over $80 \%$ of avoidable blindness according to a previous pan-India survey published in 2008 .

\section{What are the new findings?}

- The present study reports significant decline in prevalence of blindness compared with previous studies. It also establishes a changing pattern of blindness in urban India-declining proportion of cataract blindness and emerging burden of posterior segment diseases (PSDs) as cause of blindness. Cataract surgical coverage is demonstrated to be excellent in this study depicting success of control strategies.

\section{How might these results change the focus of research or clinical practice? \\ - These results emphasise the need to have similar surveys in rural areas and other states of India to see variation in prevalence and pattern of blindness. This study also identifies the need to strengthen services to operate on cataracts at earlier immature stages and to tackle the emerging burden of PSD.}

thrust in India by governmental, non-governmental and private agencies to tackle this. Resultant improvement in cataract services has decreased the proportion of blindness attributable to cataract, but surveys ${ }^{45}$ suggest more work is needed to ensure universal eye health. ${ }^{2}$

Prevalence of blindness globally has shown significant decline over past two decades ${ }^{6-9}$ and shows a wide variation across various states of India. ${ }^{45}$ This variation could be due to factors such as access to care, variable levels of economic development and social factors (housing, gender bias). ${ }^{1}$

Assessment of magnitude of blindness is crucial for planning an eye care programme 
and to assess impact of services. This requires generating disaggregated information for assisting and facilitating service delivery planning.

Pune is an urban metropolitan region having a population of 5.5 million. ${ }^{10}$ Pune city is the second largest city and an industrial, educational hub in Maharashtra state of western India. There are over 400 ophthalmologists in Pune municipal area who work in private $(70 \%)$, public $(10 \%)$ or NGO (15\%) sector and the remaining $5 \%$ do not practise (personal communication). Nearly $40 \%$ of Pune population lives in slums. Eye care services in urban marginalised populations are a challenge, and to the best of our knowledge, until now, no such organised and systematic effort exists in India. One of the important objectives of 'global action plan' 2014-2019 for universal eye health is to generate evidence on magnitude and causes of visual impairment (VI) and eye care services. ${ }^{2}$ Hence, estimating prevalence of blindness and its causes was planned through a rapid assessment of avoidable blindness (RAAB) survey in the Pune municipal corporation area to develop an evidence base for planning urban eye care services.

RAAB is a survey methodology designed for assessment of prevalence and causes of blindness and VI in the population over 50 years of age. ${ }^{11}{ }^{12}$ It has been used in over 330 population surveys of eye health worldwide. ${ }^{13}$

\section{METHODS}

The survey used the RAAB methodology along with additional diabetic retinopathy (DR) module. In the present paper, results pertaining only to RAAB module are presented. Findings of the DR module are presented elsewhere. ${ }^{14}$ Each survey team consisted of an ophthalmologist, an optometrist, a study coordinator and a technician. Three such teams were trained by a certified RAAB trainer. As part of the training, each team underwent interobserver variability (IOV) testing to check agreement on visual acuity (VA) assessment, lens examination, main cause of VI and diagnosis of DR grade between each team and a gold standard. A Kappa value of 0.6 or more was considered as acceptable. Kappa values of IOV for the first three assessments ranged between 0.86 and 0.89 and the same for grading of DR was 0.65.

\section{Sample size calculation}

Pune municipal corporation area has a population of 3 million ( $16 \%$ persons aged $>50$ years).${ }^{12}$ The sample size was calculated using the RAAB software. The estimated prevalence of DR was used as the parameter for sample size estimation, as this was one of the main objectives. A sample size of 3527 participants was calculated based on an expected prevalence of DR of $3.8 \%$ in the target age group ${ }^{15}$ and prevalence of blindness of $3.6 \%{ }^{5}$ relative precision of $22 \%$ of the estimate $( \pm 0.84 \%)$, non-compliance of $10 \%, 95 \%$ CIs and a design effect of 1.6. Using the standard RAAB approach, participants were enumerated in 60 clusters of 60 adults aged 50 and above.
Updated data from the electoral list of 2017 served as the sampling frame (most updated population data as per standard RAAB protocol). The updated electoral list included migrant workers who had moved to Pune before 2017. Electoral wards served as primary sampling units. The population ( $>18$ years) of the smallest and the largest sampling unit was 508 and 850, respectively (average population 630). Each randomly selected sampling unit was divided into multiple segments (compact segment sampling) based on the expected proportion of the population 50 and above. Given that $16 \%$ of the population are expected to be in this age group, it was calculated that an all-age segment population size of 375 would identify a cluster of approximately 60 persons above 50 years of age. Each sampling unit was therefore divided into equal segments of approximately 375 people of all ages. To avoid bias, one segment was then randomly selected by a local community leader using a folded chit lottery method from among all segments in the sampling unit. The date and time of visit was publicised at least a day prior in the survey area to minimise non-response. Two teams then visited separate areas (door-to-door visit) in the selected segment until they examined 30 persons each. If an eligible person in the household was not available/ refused or was unable to comply, he/she was considered a non-respondent. In the selected segments having highrise apartments, each team started from the opposite end (first floor and top floor). Each consecutive house was visited until 30 persons were examined by each team. In case of falling short of the required number, the team(s) went to the adjacent apartment building to complete the sample for that day. This method was implemented in the pilot cluster and found suitable in the urban setting.

\section{Examination and data collection}

Data on occupation and health insurance status were collected. There is a provision of two optional fields in standard RAAB data collection form. Aforementioned data were collected to study the association between them and the prevalence of blindness/DR as well as coverage of these services. All participants then underwent VA (presenting and pinhole) testing in each eye. VA assessment was completed using Snellen's tumbling $\mathrm{E}$ chart, and participants were labelled as having normal vision $(6 / 12$ or more)/VI (6/18-3/60)/blindness $(<3 / 60)$ as per WHO's convention and the RAAB survey methodology V.6. ${ }^{16}$ Participants then underwent anterior segment evaluation with a light source and a detailed lens examination for red glow by direct ophthalmoscope. All eyes with early VI or worse $(<6 / 12)$ were examined with a direct ophthalmoscope to ascertain the cause. Each participant was asked about history of diabetes mellitus (DM) and then underwent random blood sugar examination using a glucometer. Persons with DM were dilated as part of DR module of the RAAB to check retinal status. Fundus was examined by a trained ophthalmologist using indirect ophthalmoscope (Appasamy Associates, India) and a $20 \mathrm{D}$ lens (Volk, Germany) to ascertain DR status. 


\begin{tabular}{|c|c|c|c|}
\hline & Men & Women & Total \\
\hline Age (years) & $\mathrm{N}(\%)$ & $\mathrm{N}(\%)$ & $\mathrm{N}(\%)$ \\
\hline $50-59$ & 604 (41.9) & 841 (47.2) & 1445 (44.9) \\
\hline $60-69$ & $501(34.8)$ & 603 (33.9) & 1104 (34.3) \\
\hline $70-79$ & $246(17.1)$ & 233 (13.1) & 479 (14.9) \\
\hline$>80$ & $89(6.2)$ & $104(5.8)$ & $193(6.0)$ \\
\hline Total & $1440(100)$ & $1781(100)$ & $3221(100)$ \\
\hline
\end{tabular}

Details of the methods of DR module are presented in another paper. ${ }^{14}$ For the rest of the subjects with early VI or worse, if no obvious cataract/anterior segment or obvious posterior segment cause (such as age-related macular degeneration (ARMD), DR) was identified, eyes were labelled as having 'other' posterior segment disease (PSD).

If there was a primary and a secondary cause of blindness or VI, only the primary cause was recorded as principal cause. If there were two or more primary disorders, equally contributing to the visual loss, then the cause that was easiest to treat or to prevent was recorded as primary cause as per WHO convention. This was done for each eye as well as in the individual (better eye) as per RAAB protocol.

\section{Data entry and analysis}

Data were entered into the RAAB6 software on a daily basis by two persons separately to ensure validity and consistency. Data cleaning was performed if required before the teams went to survey next day. Descriptive statistics were generated by the RAAB 6 software. Custom analysis of causes of cataract surgical outcome data was conducted after exporting RAAB data into Excel. Statistical tests of association between categorical variables were carried out in a statistical software (Stata IC V.14; StataCorp LLC, College Station, Texas, USA).

\section{Patient and public involvement}

There was no patient involvement in planning and executing this study. A meeting was planned after completion of this survey to disseminate results to district health officials, NGO representatives and office bearers of local ophthalmology and diabetes associations as well as to general public through local print and electronic media.

\section{RESULTS}

The response rate for the survey was $89.5 \%$ (3221/3600), and $55.3 \%$ were women. Proportion of non-respondents was as follows: not available, $4.9 \%$; refusals, $4.1 \%$; unable to comply, $1.5 \%$.

Age and gender distribution of the people in the sample is shown in table 1 .

For women, the population age distribution of the examined geographical area was similar to sample distribution. However, men were under-represented in the 50-59 age group (sample $41.9 \%$ vs survey area $50.7 \%$ ) and over-represented in the older age groups (60-69, $34.8 \%$ vs $31 \%$ and $70-79,17.1 \%$ vs $13.2 \%$, respectively).

Of all the examined persons, $1444(44.8 \%)$ were daily labourers and 70 (2.1\%) did not earn wages. Also, 13.9\% (447/3221) had some form of health insurance.

Sample prevalence of blindness (not adjusted for age and sex) was $1.4 \%$ (95\% CI 1 to 1.9 ). Total prevalence of VI (early VI to blindness) was $29.8 \%$. Table 2 shows age-standardised and sex-standardised magnitude of blindness and visual impairment. Prevalence of blindness and severe VI was similar in men and women, but that of moderate VI, early VI and functional low vision was significantly higher in women than in men as shown in table 2.

Prevalence of blindness by age group is shown in table 3.

Principal causes of blindness and visual impairment are shown in table 4 . Overall, the proportion of avoidable causes of blindness/VI was as follows: blindness, $69.6 \%$; severe VI, 93\%; moderate VI, 90.2\%; early VI, $94.6 \%$.

Overall posterior segment diseases (glaucoma, DR, ARMD and other PSD) accounted for $39.1 \%$ of blindness-next only to cataract blindness. Extrapolating this proportion to the magnitude of blindness as stated in table 2 gives an estimate of persons blind from various causes as follows: cataract, 5415; overall PSD, 4633.

Table 5 shows outcome by presenting VA category. Cumulative proportion of borderline and poor outcome was $32.4 \%(385 / 1190)$.

\begin{tabular}{|c|c|c|c|c|c|c|}
\hline & \multicolumn{2}{|l|}{ Men } & \multicolumn{2}{|l|}{ Women } & \multicolumn{2}{|l|}{ Total } \\
\hline & $\mathbf{N}$ & $\%(95 \% \mathrm{Cl})$ & $\mathbf{N}$ & $\%(95 \% \mathrm{Cl})$ & $\mathbf{N}$ & $\%(95 \% \mathrm{Cl})$ \\
\hline Blindness & 6365 & 1.4 (0.8 to 2.1$)$ & 5487 & $1.3(0.7$ to 1.8$)$ & 11852 & 1.3 (0.9 to 1.8$)$ \\
\hline Severe $\mathrm{VI}$ & 5692 & 1.4 (0.8 to 1.9$)$ & 5667 & 1.3 (0.8 to 1.8$)$ & 11360 & $1.3(0.9$ to 1.7$)$ \\
\hline Moderate VI & 47515 & 10.6 (8.7 to 12.4$)$ & 67293 & 15.4 (13.1 to 17.8$)$ & 114807 & $13.0(11.2$ to 14.7$)$ \\
\hline Early VI & 53056 & $11.8(10$ to 14.4$)$ & 72761 & 16.7 (14.5 to 18.8$)$ & 125820 & $14.2(12.7$ to 15.7$)$ \\
\hline Functional low vision & 5094 & 1.1 (0.6 to 1.7$)$ & 11132 & 2.6 (1.8 to 3.3 ) & 16230 & 1.8 (1.3 to 2.3 ) \\
\hline
\end{tabular}

VI, visual impairment. 
Table 3 Blindness prevalence by age group

\begin{tabular}{|c|c|c|c|c|c|c|}
\hline & \multicolumn{2}{|c|}{ Men } & \multicolumn{2}{|c|}{ Women } & \multicolumn{2}{|c|}{ Total } \\
\hline & $\mathbf{N}$ & $\%(95 \% \mathrm{Cl})$ & $\mathbf{N}$ & $\%(95 \% \mathrm{Cl})$ & $\mathbf{N}$ & $\%(95 \% \mathrm{Cl})$ \\
\hline $50-59$ years & 2 & 0.3 (0.0 to 0.8$)$ & 5 & $0.6(0.1$ to 1.1$)$ & 7 & 0.5 (0.1 to 0.9 ) \\
\hline $60-69$ years & 7 & 1.4 (0.4 to 2.4$)$ & 5 & 0.8 (0.1 to 1.5$)$ & 12 & $1.1(0.5$ to 1.7$)$ \\
\hline $70-79$ years & 12 & 4.9 (2.4 to 7.4$)$ & 5 & 2.2 (0.4 to 3.9$)$ & 17 & 3.6 (2.1 to 5.0$)$ \\
\hline $80+$ years & 3 & 3.4 (0.0 to 7.2 ) & 7 & 6.7 (1.7 to 11.7$)$ & 10 & 5.2 (1.7 to 8.7$)$ \\
\hline All $50+$ years & 24 & 1.7 (1.0 to 2.3$)$ & 22 & $1.2(0.7$ to 1.8$)$ & 46 & $1.4(1.0$ to 1.9$)$ \\
\hline
\end{tabular}

Of all the eyes operated on for cataract, 18 (1.5\%) were aphakic. Of the 385 persons with borderline/ poor outcome, 121 were men and 164 were women. Causes of borderline/poor outcome by gender were as follows: ocular comorbidity-men 59 (48.8\%), women 141 (53.4\%); surgical complications-men 18 (14.8\%), women $50(18.9 \%)$; refractive error-men 13 (10.8\%), women $28(10.6 \%)$; postoperative complications-men $31(25.6 \%)$, women $45(17.1 \%)$.

Cataract surgical coverage (CSC-proportion of individuals operated on, of all cataract cases) was $96.7 \%$ (men $95.6 \%$ vs women $97.5 \%$ ) for those with blindness and $92.8 \%$ (men $91.5 \%$ vs women $93.6 \%$ ) for those with severe VI. There was no gender disparity as far as CSC was concerned. Occupation and insurance status of the participants were not associated with cataract surgical status $(\mathrm{p}>0.5)$.

'Need not felt' (15/41, 36.6\%; men $31.6 \%$ vs women $40.9 \%)$ and 'cost' $(13 / 41,31.7 \%$; men $47.4 \%$ vs women $18.2 \%$ ) were the most common barriers for cataract surgery.
All data relevant to the study are included in the article or uploaded as online supplementary information (online supplementary files 1-7).

\section{DISCUSSION}

In the last decade, several RAAB surveys have been conducted in India ${ }^{5}$ and globally. ${ }^{17-22}$ In the previous pan-India RAAB study, ${ }^{5} 21.5 \%$ of the population was from urban region and the rest from rural region. Pune municipal area where the present survey was conducted is an urban, densely populated region in western India. Nearly $40 \%$ of the population in this area resides in slums. Eye care services in this region are provided by government, private or NGO facilities. With a high number of ophthalmologists, accessibility of services is expected to be good.

Response rate for the survey was very good (89.5\%). There was slight under-representation of men in the younger age group and over-representation in the older age group. This was because most men in the working age were away during the survey period. There was no gender difference in prevalence of blindness. Western

Table 4 Principal causes of blindness and visual impairment in persons

\begin{tabular}{|c|c|c|c|c|}
\hline & Blindness & Severe VI & Moderate VI & Early VI \\
\hline Cause & $\mathrm{N}(\%)$ & $\mathrm{N}(\%)$ & $\mathrm{N}(\%)$ & $\mathrm{N}(\%)$ \\
\hline 1. Refractive error & $1(2.2)$ & $1(2.3)$ & $59(13.4)$ & $214(44.7)$ \\
\hline 2. Aphakia (uncorrected) & $0(0.0)$ & $0(0.0)$ & $0(0.0)$ & $0(0.0)$ \\
\hline 3. Cataract untreated & $21(45.7)$ & $34(79.1)$ & $293(66.6)$ & $202(42.2)$ \\
\hline 4. Cataract surgical complications & $3(6.5)$ & $3(7.0)$ & $36(8.2)$ & $35(7.3)$ \\
\hline 5. Trachomatous $\mathrm{CO}$ & $0(0.0)$ & $0(0.0)$ & $0(0.0)$ & $0(0.0)$ \\
\hline 6. Non-trachomatous CO & $2(4.3)$ & $2(4.7)$ & $5(1.1)$ & $0(0.0)$ \\
\hline 7. Phthisis & $1(2.2)$ & $0(0.0)$ & $0(0.0)$ & $0(0.0)$ \\
\hline 8. Onchocersiasis & $0(0.0)$ & $0(0.0)$ & $0(0.0)$ & $0(0.0)$ \\
\hline 9. Glaucoma & $4(8.7)$ & $0(0.0)$ & $1(0.2)$ & $2(0.4)$ \\
\hline 10. Diabetic retinopathy & $0(0.0)$ & $0(0.0)$ & $3(0.7)$ & $0(0.0)$ \\
\hline 11. ARMD & $2(4.3)$ & $1(2.3)$ & $7(1.6)$ & $8(1.7)$ \\
\hline 12. Other PSD & $12(26.1)$ & $2(4.7)$ & $36(8.2)$ & $17(3.5)$ \\
\hline 13. Globe/CNS abnormalities & $0(0.0)$ & $0(0.0)$ & $0(0.0)$ & $1(0.2)$ \\
\hline Total & $46(100)$ & $43(100)$ & $440(100)$ & $479(100)$ \\
\hline
\end{tabular}

ARMD, age-related macular degeneration; CNS, central nervous system; CO, corneal opacity; PSD, posterior segment disease; VI, visual impairment. 


\begin{tabular}{|c|c|c|c|}
\hline & Men & Women & Total \\
\hline & $\mathbf{N}(\%)$ & $\mathrm{N}(\%)$ & $\mathrm{N}(\%)$ \\
\hline Very good: can see $6 / 12$ & $250(53.8)$ & $312(43.0)$ & $562(47.2)$ \\
\hline Good: can see 6/18 & $94(20.2)$ & $149(20.6)$ & $243(20.4)$ \\
\hline Borderline: can see $6 / 60$ & $76(16.3)$ & $194(26.8)$ & $270(22.7)$ \\
\hline Poor: cannot see $6 / 60$ & $45(9.7)$ & $70(9.7)$ & $115(9.7)$ \\
\hline Total & 465 (100) & 725 (100) & $1190(100)$ \\
\hline
\end{tabular}

Maharashtra and Pune in particular is known to have less gender bias, indicators being maternal mortality and childhood mortality rates among the lowest in the country and participation of female work force being higher than the national average. ${ }^{23}$ However, higher prevalence of moderate VI (MVI), early VI (EVI) and functional low vision among women is suggestive of gender bias when it comes to accessing eye care.

Overall prevalence of blindness was $1.3 \%$ (95\% CI 0.9 to 1.8). This prevalence is much less than a previous nationwide RAAB survey where the prevalence was $3.6 \%$ (urban sample-2.9\%). ${ }^{5}$ The prevalence of blindness in the present study is half of that reported from urban regions in the previous study. There are no baseline data available from Pune and the previous RAAB data from other parts of India cannot be directly compared with findings from the present study. However, it could be hypothesised that low prevalence is suggestive of a strong commitment of stakeholders to implement strategies of the National Program for Control of Blindness, India. The prevalence of blindness showed a rising trend with advancing age. Higher prevalence of blindness with increasing age clearly explains association between increased longevity and blinding eye diseases. Wide $95 \%$ CI of the prevalence values in higher age groups ( $>70$ years) was because the sample in that age group was much smaller.

Cataract surgical coverage was excellent and equitable between genders for those blind due to cataract. Cataract surgical rate of close to 6000 as well as high ratio of over 130 ophthalmologists per million population is perhaps responsible for a very high CSC in Pune city. Hence, access to cataract services is not a major barrier and there is no gender disparity for uptake of these services. Low prevalence of blindness compared with previous RAAB survey and good CSC means persons with cataract are accessing eye care services early. Strengthening of the eye health system and partnership building between government and NGOs is necessary to tackle increasing workload of immature cataracts.

Despite excellent CSC, cataract still accounted for nearly half of the causes of blindness. Overall posterior segment diseases accounted for next common causes. With improving socioeconomic status and better access to cataract services, proportion of blindness due to PSD is likely to increase in urban India. Glaucoma accounted for $8.7 \%$ of the blindness. This proportion is almost double the previous estimates $(4.4 \%) .^{5}$ There is also a possibility that in participants with coexisting glaucoma and cataract, the latter was selected as the principal cause of blindness leading to underestimates of glaucoma diagnosis. Cataract was the most common cause of severe VI and MVI. Uncorrected refractive errors accounted for most cases of EVI. Intervention in the form of spectacles can lead to significant reduction in prevalence of EVI.

In the present study, a third of the participants operated on for cataract had borderline/poor outcome. In urban pockets of Argentina (similar prevalence of blindness and similar CSC), less than a fifth of cataract cases operated on had borderline/poor visual outcome. ${ }^{24}$ Nearly half $(46.5 \%)$ of the causes of borderline/poor outcome in the present study were either treatable or preventable. They included posterior capsule opacity, surgical complications and refractive error in that order of frequency. Ocular comorbidities and surgical complications as causes of poor/borderline outcome were more common in women and postoperative complications were more common in men. Strengthening cataract surgical training programmes and closely monitoring surgical outcomes can help reduce the rate of surgical complications further. These findings also emphasise the need to improve access to simple interventions such as YAG capsulotomy. The proportion of men with "very good' outcome was higher than that of women whereas in 'borderline outcome' category, there were more women. This 'very good' outcome does have clinical/visual function significance in those who have undergone cataract surgery.

The most common barrier for accessing cataract surgical services was 'need not felt', and this was more commonly reported by women than by men. This could be because women in Asian societies have a different health-seeking behaviour and they often access care late due to lack of felt need. ${ }^{25}$ At the root of this may lie a larger issue of lack of women empowerment and women feeling more dutybound towards their domestic responsibilities. 'Cost' was a barrier reported by nearly a third of those blind due to cataract, more so by men. This underlines the financial challenges faced by urban poor in accessing services. National Urban Health Mission envisages to meet healthcare needs of the urban poor, by providing essential healthcare services and reducing their out-of-pocket expenses for treatment. ${ }^{26}$

Using this approach can present a good baseline for organising and planning eye care services for the underprivileged community in Pune. Partnership with NGOs/ other stakeholders for providing services would benefit the urban poor. Social marketing of cataract services in the poor areas might improve uptake further.

The findings of this study were disseminated through a meeting with municipal health authorities, district ophthalmic surgeon, president of local ophthalmology society and other important stakeholders such as secretaries of associations for senior citizens and persons with DM. Facilities providing free surgeries/treatment 
for poor were identified and linked with senior citizen groups and local community leaders. Findings were also disseminated through local print and electronic media to encourage needy persons to seek care.

There are certain limitations to this study. This was carried out in an urban area of a relatively developed state of Maharashtra. Hence, results of this survey may not be generalisable to rural parts of the state/India. Baseline data for the survey region were not available; hence, it cannot be said whether or not prevalence of blindness is on the decline.

In conclusion, looking at findings from the present study and from urban data of previous RAAB survey in India, ${ }^{5}$ it can be hypothesised that prevalence of blindness is showing a declining trend in urban pockets of India. Cataract still remains a major cause of blindness despite excellent surgical coverage, with PSD emerging as an important cause. Health systems in cities need to be strengthened to tackle cataracts at early stages.

Acknowledgements The authors would like to acknowledge the following people: Mr Nitin Desai, Chairman, Desai Brothers Pvt Ltd, for supporting this research and free services for patients identified through this research; Sandip Anjankar and the entire RAAB team of H V Desai Eye Hospital for the field work; and Sarah Wallace for active participation and valuable inputs during the dissemination meeting.

Contributors SuK: concept, implementation, data analysis and interpretation, writing manuscript, submission of the manuscript. ShK: implementation, data collection, analysis, interpretation, writing manuscript. IM: implementation, data analysis, interpretation, critical review of the manuscript. BRS: implementation, data analysis, interpretation, critical review of the manuscript. AL: implementation, data collection, interpretation, critical review of the manuscript. RM: implementation, data collection, interpretation, critical review of the manuscript. JK: implementation, data collection, critical review of the manuscript. RK: implementation, interpretation of data, critical review of the manuscript. KD: implementation, interpretation of data, critical review of the manuscript. MD: implementation, interpretation of data, critical review of the manuscript.

Funding Grant for this survey was provided by Desai Brothers Pvt Ltd, Pune, India. Competing interests None declared.

Patient consent for publication Obtained.

Provenance and peer review Not commissioned; externally peer reviewed.

Open access This is an open access article distributed in accordance with the Creative Commons Attribution Non Commercial (CC BY-NC 4.0) license, which permits others to distribute, remix, adapt, build upon this work non-commercially, and license their derivative works on different terms, provided the original work is properly cited, appropriate credit is given, any changes made indicated, and the use is non-commercial. See: http://creativecommons.org/licenses/by-nc/4.0/.

\section{REFERENCES}

1. Ulldemolins AR, Lansingh VC, Valencia LG, et al. Social inequalities in blindness and visual impairment: a review of social determinants. Indian J Ophthalmol 2012;60:368-75.

2. World Health Organization. Universal eye health: a global action plan 2014-2019, 2014. Available: http://www.who.int/blindness/AP2014_ 19_English.pdf [Accessed Apr 2017].
3. Pizzarello L, Abiose A, Ffytche T, et al. Vision 2020: the right to sight: a global initiative to eliminate avoidable blindness. Arch Ophthalmol 2004;122:615-20.

4. Murthy GVS, Vashist P, John N, et al. Prevelence and causes of visual impairment and blindness in older adults in an area of India with a high cataract surgical rate. Ophthalmic Epidemiol 2010:17:185-95.

5. Neena J, Rachel J, Praveen V, et al. Rapid assessment of avoidable blindness in India. PLoS One 2008;3:e2867.

6. Stevens GA, White RA, Flaxman SR, et al. Global prevalence of vision impairment and blindness: magnitude and temporal trends, 1990-2010. Ophthalmology 2013;120:2377-84.

7. Dandona L, Dandona R, Srinivas $M$, et al. Blindness in the Indian state of Andhra Pradesh. Invest Ophthalmol Vis Sci 2001;42:908-16.

8. Murthy G, Gupta SK, John N, et al. Current status of cataract blindness and vision 2020: the right to sight initiative in India. Indian $J$ Ophthalmol 2008;56:489-94.

9. Bourne RRA, Flaxman SR, Braithwaite T, et al. Magnitude, temporal trends, and projections of the global prevalence of blindness and distance and near vision impairment: a systematic review and metaanalysis. Lancet Glob Health 2017;5:e888-97.

10. Census Organization of India. Population census of India, 2011. Available: http://www.census2011.co.in/census/city/375-pune.html [Accessed Mar 2017].

11. Brendan D, Faal H, Foster A. A proposed rapid methodology to assess the prevalence and causes of blindness and visual impairment. Ophthalmic Epidemiol 2006;13.

12. Kuper H, Limburg H, Polack S. Rapid assessment of avoidable blindness. J Ceh 2006:19.

13. RAAB Repository health information services, the Netherlands. Available: www.raabdata.info/repository [Accessed Apr 2017]

14. Kulkarni S, Kondalkar S, Mactaggart I, et al. Estimating the magnitude of diabetes mellitus and diabetic retinopathy in an older age urban population in Pune, Western India. BMJ Open Ophthalmol 2019;4:e000201.

15. Raman R, Rani PK, Reddi Rachepalle S, et al. Prevalence of diabetic retinopathy in India: Sankara Nethralaya diabetic retinopathy epidemiology and molecular genetics study report 2. Ophthalmology 2009;116:311-8.

16. International Centre for Eye Health. RAAB6. Available: https://www. cehjournal.org/resources/raab/ [Accessed Mar 2017].

17. Kandeke L, Mathenge W, Giramahoro C, et al. Rapid assessment of avoidable blindness in two northern provinces of Burundi without eye services. Ophthalmic Epidemiol 2012;19:211-5.

18. Mathenge $\mathrm{W}$, Kuper $\mathrm{H}$, Limburg $\mathrm{H}$, et al. Rapid assessment of avoidable blindness in Nakuru district, Kenya. Ophthalmology 2007;114:599-605

19. Mathenge W, Nkurikiye J, Limburg $\mathrm{H}$, et al. Rapid assessment of avoidable blindness in Western Rwanda: blindness in a postconflict setting. PLoS Med 2007:4:e217.

20. Polack S, Yorston D, López-Ramos A, et al. Rapid assessment of avoidable blindness and diabetic retinopathy in Chiapas, Mexico. Ophthalmology 2012;119:1033-40.

21. Xiao B, Kuper H, Guan C, et al. Rapid assessment of avoidable blindness in three counties, Jiangxi Province, China. $\mathrm{Br} J$ Ophthalmol 2010;94:1437-42.

22. Zatic T, Bendelic E, Paduca A, et al. Rapid assessment of avoidable blindness and diabetic retinopathy in Republic of Moldova. $\mathrm{Br} J$ Ophthalmol 2015;99:832-6.

23. World Bank Group. Maharashtra gender report, 2012. Available: http://documents.worldbank.org/curated/en/685741504170989654/ pdf/119251-BRI-P157572-Maharashtra-Gender.pdf [Accessed April, 2017].

24. Barrenechea R, de la Fuente I, Plaza RG, et al. [National survey of blindness and avoidable visual impairment in Argentina, 2013]. Rev Panam Salud Publica 2015;37:7-12.

25. Dhaliwal U, Gupta SK. Barriers to the uptake of cataract surgery in patients presenting to a hospital. Indian J Ophthalmol 2007;55:133.

26. Ministry of Health and Family Welfare, Government of India. National urban health mission, 2013. Available: http://nhm.gov.in/nhm/nuhm. html [Accessed Mar 2017]. 